\title{
Profitable working capital management in industrial maintenance companies
}

\begin{abstract}
Purpose - The purpose of this paper is to analyze the impact of working capital management on profitability in industrial maintenance service companies.

Design/methodology/approach - Analytical modeling has been used as the research method. Finnish industrial maintenance companies have been analyzed on the basis of their financial statements.

Findings - We reveal a significant negative correlation between the cycle times of operational working capital and the return on investment of industrial maintenance companies. Ligth fixed assets and good profitability of the maintenance sector emphasize the importance of working capital management. Large maintenance service companies seem to achieve competitive advantage over small and medium sized maintenance service providers through both fixed assets- and working capital-related economies of scale, and through the fact that large maintenance service providers often focus on providing services mostly for their host companies.
\end{abstract}

Research limitations - The scarcity of large enterprises in the market in question precludes the use of a more extensive sample in the analysis.

Practical implications - In the industrial maintenance service business, more attention should be paid to active management of working capital. We can conclude that this holds true especially in large industrial maintenance service enterprises.

Originality/value - We contribute to the unexplored perspective of industrial maintenance companies. Previous studies of industrial maintenance companies have not addressed working capital management, which gains more and more attention under the volatile economic circumstances of the present day.

Keywords Industrial maintenance services, Profitability, Working capital, Flexible asset management model

Paper type Research paper

\section{Introduction}

The focus of this paper is on the working capital management of industrial maintenance service providers. There is not much previous research about industrial maintenance service providers, although maintenance performance has grown to be of high importance to industrial companies (e.g. Al-Turki 2011; Simões et al., 2011). Previous research has been mainly done from the point of view of service buyers, concerning mostly outsourcing. On the other hand, several researchers have already linked the asset management perspective to the company-level goals and profitability (e.g. Aoudia et al., 2008; Tam and Price 2008). Considering the present state of industrial services, the global trend towards networking and focusing on core competences has led to some notable changes (Broedner et al., 2009; Boulaksil and Fransoo, 2010; Holschbach and Hofmann, 2011). A vast majority of outsourced business functions can be classified as services (Bailey et al., 2002; Benson and Ieronimo, 1996; Kakabadse and Kakabadse, 2002; Harland et al., 2005; McIvor et al., 2009). Bailey et al. (2002) reported that 70\% of the companies in their research sample had outsourced one or more of their business functions. Gradually the outsourcing practice has extended to more and more important functions (Harland et al., 2005; Hui and Tsang, 2006). Consequently an increasing demand for a variety of industrial services has emerged. This has led to a great number of start-up industrial service companies throughout the world (Hilletofth and Hilmola, 2010). The industrial maintenance of manufacturing enterprises is one of the services outsourced more and more often (Tarakci et al., 2009). In an international survey conducted by the European Federation of National Maintenance Societies (2011), 24\% of the surveyed companies had outsourced their maintenance activities. Campbell (1995) states that in his survey implemented in North America, 35\% of the companies had outsourced at least some part of their maintenance activities.

Operational working capital management, including inventories, accounts receivable and accounts payable, is an important part of short-term finance and asset management. The past economic crisis raised the interest towards more efficient working capital management. This also increased the academic interest towards the topic. The determinants of working capital management and the relation between working capital management and profitability have been studied by several researchers (e.g. Chiou et al., 2006; Deloof, 2003; Hill et al., 2010). Broad, cross-industry statistical analyses have concluded that companies should apply aggressive strategy to manage their operational working capital, which means shortening the cycle times of inventories, accounts receivable and increasing the cycle time of accounts payable. It should be noted, however, that minimizing working capital is not always the most rational option; instead the cycle times of working capital should be actively optimized and managed according to contextual factors. The literature has not considered individual industries regarding working capital management strategies. In addition, prior research has indicated a range of variables affecting working capital management, but there is still not a clear view of what the affecting variables are and how great their impact is. Also, the focus of previous research has been on manufacturing industries. The special characteristics of service industries have mostly been neglected in studies related to working capital management. 
The objective of this paper is to examine the role of working capital and its impact on the return on investment, ROI, in the industrial maintenance service sector. The research questions of this paper are the following:

\section{What is the effect of working capital management on the return on investment in the industrial maintenance service companies?}

What are the main differences between small and medium size enterprises and large enterprises in the maintenance service sector regarding the cycle times of working capital?

How can a target return on investment be achieved through the management of the cycle times of working capital in the dynamic future of industrial maintenance service companies?

Modeling has been used as the research method in this paper. The flexible asset management model (henceforth called the FAM model) connects working capital management and the ROI, and can be used to observe the impact of working capital management on relative profitability. By analyzing working capital with an analytical model, new insights to the effects of other variables affecting the working capital management-profitability relationship can be observed. The model could be used on a customer or supplier level in contract-bound industries to control the terms of contracts from the perspective of profitability. In this paper we approach some of the managerial implications of the FAM model by analyzing industrial maintenance companies.

This paper sheds light on the working capital management in industrial maintenance service companies. Our empirical analysis is done on the basis of the financial statements of 18 Finnish industrial maintenance companies. We show that also service sector needs to take working capital into account, and that companies can increase their profitability by more efficient cycle time of working capital. The impact of working capital is even larger than in capital intensive manufacturing industries. The industrial maintenance service sector is still relatively unknown from academic point of view. This research uncovers new information about the economic state and development of these service providers. It is also noteworthy that this paper accumulates information about the differences between large, and small and medium size maintenance service providers (SMEs).

\section{Working capital management and profitability}

Working capital is a part of a firm's capital employed such as fixed assets. Broadly, net working capital is defined as current assets less current liabilities and it measures the financial health of a company. Working capital can also be defined from the operational perspective as inventories plus accounts receivable less accounts payable. We concentrate on operational working capital in this paper. A large amount of working capital ties up funds and can also indicate problems in the operations of a company. Although discussed in textbooks of finance and management accounting, working capital management has received relatively little attention in the academic research (Viskari et al., 2011), which has traditionally concentrated on long-term capital (Chiou et al., 2006), and asset management has mostly concerned fixed assets (Komonen, 2010).

The management of operational working capital is balancing between the reduction of capital tied up to the processes and current assets, which increases profitability, and minimizing the adverse effects caused by too small amount of operational working capital. If the inventory levels are too low, possible interruptions of production, delivery problems, business losses due to scarcity of products, and price fluctuations may cause extra costs (Blinder and Maccini, 1991). Decrease in trade credits granted to customers drops sales (Molina and Preve, 2009), and may harm the relationships with customers (Ng et al., 1999). In addition, paying suppliers with long payment periods mean that discounts for early payments cannot be utilized (Wang, 2002). The interesting question of management is, whether these arguments for long cycle times offset the benefits of reducing working capital. However, answering this question is not a part of the core contents of this paper.

Statistical analyses of the relation between working capital management and profitability have concluded that it is more beneficial for a company to aim for a shorter cycle time of operational working capital and reduce tied-up capital and total assets than to operate with long cycle times (e.g. Deloof, 2003; García-Teruel and Martínez-Solano, 2007; Lazaridis and Tryfonidis, 2006). Besides profitability, the shorter cycle time also improves the liquidity and productivity of a company (Johnson and Templer, 2011). The data of the previous studies has been gathered from large databases, which has enabled large samples. With this kind of research design, statistically significant results can be found, but the previous literature lacks the perspective of individual industries. As we know, there are huge differences in the capital structures, investment logics and profitability between industries. In addition, even if previous literature has found the negative correlation between the cycle time of working capital and profitability, it is still unknown how great the impact of working capital management on profitability actually is. Could managers really affect the return on investment through working capital management or is the relation between the variables insignificant in practice?

According to Reed and Storrud-Barnes (2009), most management theories have concentrated on manufacturing companies, while differences and similarities to service providers have been neglected. Thus the applicability of practical contributions to the service sector often remains unsettled. In many respects this holds true also in studies of working capital management. In some studies of working capital management, service providers have been excluded from the sample in advance (see e.g. Deloof, 2003; Dong and Su, 2010). Other studies have included service providers alongside manufacturing companies (see e.g. BañosCaballero et al., 2010; Jose et al., 1996). It can be noticed in these studies that the cycle time of operational working capital, cash conversion cycle (CCC), appears to be significantly shorter for service providers than for manufacturing industries. However, this observation has not yet been discussed further, and thus it is reasonable to conduct further research on this subject. 


\section{The emergence of the industrial maintenance service sector in Finland}

The role of maintenance is significant and still increasing in Finland due to relatively aged industrial assets: a vast majority of the production investments of Finnish industrial companies are nowadays directed to countries with inexpensive work force (Komonen, 2009). The average age of equipment in Finnish industries has thus increased to over 17 years (The Finnish Maintenance Society, 2007). Kornev (2009) states that the base-line for the age of industrial equipment in developed countries is between six and eight years. The structure of the maintenance sector in Finland has changed dramatically in the past decades, greatly because of the trend toward networking and focusing on core competences. Networking is not a very recent phenomenon: Miles and Snow introduced the concept of dynamic networks already in 1986 (Miles and Snow, 1986). Since then, networking has developed to be a universal trend and long-term partnerships have become more and more common (Duffy, 2008). The core competences of a company, on the other hand, were first introduced by Prahalad and Hamel (1990). In twenty years close competition has boosted the willingness of industrial manufacturing companies to concentrate on their core competences and outsource some of their supportive business functions to other companies (Hendry, 1995; Kakabadse and Kakabadse, 2002; Kremic et al., 2006; Kumar and Kumar, 2004; Redondo-Cano and Canet-Giner, 2010).

Industrial maintenance outsourcing is relatively extensive in Finland. The Finnish Maintenance Society (2007) states that out of the 50000 people employed in industrial maintenance in Finland, 15000 are employed by maintenance service providers. According to this indicator, 30\% of Finnish industrial maintenance has been outsourced. One major element behind this phenomenon is striving for economies of scale in maintenance actions. The recent profitability problems of the forest industry have further increased maintenance outsourcing in Finland. Forest companies have struggled to cut down the costs and to outsource anything but their most crucial core functions.

Both the significance of maintenance performance to industrial companies, and the fact that long-term relationships are becoming more and more common in maintenance highlight the role of contracts in the industrial maintenance business. Contracts in outsourced services and in maintenance have been addressed in scientific research (e.g. Campbell, 1995; Kumar et al., 2004; Martin, 1997; Ngwenyama and Bryson, 1999). However, the perspective of the maintenance service provider remains somewhat unexplored, and the perspective of the customer has been strongly emphasized instead. However, also the maintenance service providers must have in advance a good idea of how changes in the contract affect their profitability. Elements to be considered include for example the terms of payment and the ownership of spare parts and assets to be maintained.

\section{Methodology}

Analytical modeling has been used as a research method in this study. Demski (2007) describes this method as using deductive logic in representing a concept or a process. The advantage of using modeling is transparency, which leads to high internal validity. The FAM model is applied to industrial maintenance business by using an empirical analysis, which is done with the financial statements of 18 Finnish industrial maintenance companies. Though small, the analyzed sample represents a remarkable share of the Finnish industrial maintenance sector. The 3893 people employed by these 18 enterprises cover approximately $26 \%$ of the employees of the whole sector. The sample net sales of 472 million euro, on the other hand, represents approximately $13 \%$ of the sum used yearly in industrial maintenance in Finland. (The Finnish Maintenance Society, 2007) The enterprises selected to the sample are listed in table I together with their personnel numbers and net sales. The sample has been selected by utilizing the membership list of the Finnish Maintenance Society. Structurally the sample represents the Finnish industrial maintenance sector well, consisting of a few large enterprises and mostly SMEs. The sample has been divided into large enterprises and SMEs according to the European Commission recommendation 2003/361/EC (European Commission, 2009). Maintenance companies from outside Finland were excluded from the study because the required data was not within reach. Probability sampling has not been used because a complete list of suitable enterprises was not available.

It was considered crucial that the sample especially reflects the features of industrial maintenance business. Thus, when selecting the sample, only enterprises whose focus was mainly in industrial maintenance were accepted, which means that equipment manufacturers and enterprises offering infrastructural maintenance services were delimited from the sample. Also the smallest micro enterprises were left out of this research. The final criteria of belonging to the sample were that the enterprises had existed for the whole period of analysis, 2004-2008, and their financial statements were available for this period. A period of five years has been chosen because the analysis is to give a clear, comprehensive understanding about the relationship between working capital management and profitability in Finnish industrial maintenance enterprises. At the time of collecting the data, the financial statements of subsequent fiscal years were not yet available through the chosen database. The financial statement data was collected using the Voitto+ database (ISSN 1459-9457). This database is maintained by Suomen Asiakastieto Ltd. (loose translation Finnish Customer Information), which in Finland is a leading service enterprise providing corporate information broadly considered to be reliable and objective.

Given the sampling criteria discussed above, five large enterprises suitable for the analysis were found. Considering that the maintenance sector still evolves quite rapidly, a more extensive sample of large maintenance providers can be selected probably in a few years' time. 13 maintenance SMEs were included in the analysis in order to reach a representative sample. Large enterprises and SMEs are mostly analyzed separately, but the average values of the whole sample are also used. It is thus justified to have more SMEs than large enterprises in the sample to simulate the actual structure of the maintenance industry. 
Table I. The enterprises selected for the research

\begin{tabular}{lrr}
\hline Large enterprises & Personnel in 2007 & Net Sales in 2007, M€ \\
\hline Fortek Ltd. & 858 & 118.2 \\
Varenso Ltd. & 473 & 83.4 \\
Konecranes Service Ltd. & 516 & 78.9 \\
Botnia Mill Service Ltd. & 591 & 73.9 \\
Kymenso Ltd. & 743 & 45.0 \\
\hline Large enterprises in total & 3181 & 399.4 \\
\hline SMEs & Personnel in 2007 & Net Sales in 2007, M€ \\
\hline ISS Teollisuuspalvelut Ltd. & 104 & 12.5 \\
Tespal Ltd. & 53 & 9.4 \\
Machinery Service Finland Ltd. & 92 & 8.4 \\
Maintpartner Industrial Services Ltd. & 109 & 8.0 \\
Pikoteknik Ltd. & 50 & 7.3 \\
Tormets Ltd. & 103 & 6.3 \\
Mahro Ltd. & 25 & 5.5 \\
Betamet Service Ltd. & 48 & 3.9 \\
Astepa Ltd. & 46 & 3.1 \\
Metso Mill Service Kauttua Ltd. & 36 & 2.6 \\
Kangasalan Pajaservice Ltd. & 16 & 2.6 \\
JTT Konepaja Ltd. & 20 & 2.2 \\
Rauman Sähkökonehuolto Ltd. & 10 & 0.8 \\
\hline SMEs in total & 712 & 72.6 \\
\hline All enterprises in total & 393 & 472.0 \\
\hline
\end{tabular}

\section{Flexible asset management model}

Kärri (2007) has constructed a model for forecasting the investment needs (consisting of fixed assets and net working capital) of a company or an industry under changing sales. Kärri argues that companies have or should have a long-term target $R O I$ level. When the fluctuation of sales is great, the capital structure should be flexible. This means that investments on the fixed assets but also investments on the working capital should be tied down to sales. Kärri's model observes the net working capital rate, but the FAM model used in this paper highlights working capital management when cycle times are added to the model.

The starting point of the FAM model is the basic function of the return on investment. As financial statements are used as a data source, the model is also derived from the balance sheet items. The ROI is determined as a function of the operating income $(E B I T)$ and the capital invested $(C)$.

$$
R O I=\frac{E B I T}{C}
$$

The depreciations and amortizations $(D)$ can be separated from the EBIT. If the capital employed is described with the assets of the balance sheet, it consists of the fixed assets $(F A)$ and the net working capital $(N W C)$ which together equal the equity plus long-term loans.

$$
R O I=\frac{E B I T D A-D}{N W C+F A}
$$

The net working capital can be divided further to current assets $(C A)$ less current liabilities $(C L)$.

$$
R O I=\frac{E B I T D A-D}{C A-C L+F A}
$$

Further, operational working capital components, inventories (INV), the accounts receivable $(A R)$ and the accounts payable $(A P)$, can be separated from the current assets and the current liabilities leaving the other current assets $(O C A)$ and the other current liabilities $(O C L)$ consisting of non-operational working capital items, such as the cash and cash equivalents and the current portion of long-term liabilities.

$$
R O I=\frac{E B I T D A-D}{I N V+A R-A P+O C A-O C L+F A}
$$

With the help of the fixed assets $(F A)$ and the yearly depreciations and amortizations $(D)$, the average depreciation period $(B)$ can be calculated as follows 


$$
B=\frac{(F A+D)}{D}=\frac{F A}{D}+1
$$

and when turned around

$$
D=\frac{F A}{B-1}
$$

Applying this definition of the depreciations and amortizations $(D)$ to the original model gives

$$
R O I=\frac{E B I T D A-\frac{F A}{B-1}}{I N V+A R-A P+O C A-O C L+F A}
$$

Cycle times have been used in many studies to measure the operational working capital management. Many studies use the cash conversion cycle $(C C C)$ to measure the working capital management. We also apply this approach and observe working capital management through cycle times. For this the FAM model is deduced further. The $C C C$ is defined through three components, the cycle time of inventories $(D I O)$, the cycle time of accounts receivable $(D S O)$ and the cycle time of accounts payable $(D P O)$

$$
C C C=D I O+D S O-D P O
$$

The cycle times of inventories (days inventories outstanding) can be calculated as the inventories divided by sales $(S)$.

$$
D I O=\frac{I N V}{S} \cdot 365
$$

Similarly the cycle time of accounts receivable (days sales outstanding) is

$$
D S O=\frac{A R}{S} \cdot 365
$$

and the accounts payable (days payables outstanding)

$$
D P O=\frac{A P}{S} \cdot 365
$$

We can also determine the cycle time of other net working capital components in a similar manner. When the cycle time of other current assets and the cycle time of other current liabilities are combined, we get the residual $(r)$.

$$
r=\frac{O C A}{S} \cdot 365-\frac{O C L}{S} \cdot 365
$$

In order to calculate the ROI using the cycle time defined above, equation (7) has to be divided by sales $(S)$. When doing so we can write the equation using only percentages $(E B I T D A / S=E B I T D A \%$ and $F A / S=F A \%)$, and cycle times as parameters

$$
R O I=\frac{E B I T D A \%-\left(F A \% \cdot \frac{1}{B-1}\right)}{\frac{D I O}{365}+\frac{D S O}{365}-\frac{D P O}{365}+\frac{r}{365}+F A \%}
$$

and when combining the components of the operating working capital, we can write

$$
R O I=\frac{E B I T D A \%-\left(F A \% \cdot \frac{1}{B-1}\right)}{\frac{C C C}{365}+\frac{r}{365}+F A \%}
$$

The $R O I$ is thus determined by five parameters. Besides the cycle time of operational working capital $(C C C)$, also the profit margin $(E B I T D A \%)$, the fixed asset ratio $(F A \%)$, the average depreciation period $(B)$ and the cycle time of residual $(r)$ affect the relative profitability. The $R O I$ increases if ceteris paribus the $E B I T D A \%$ or the $B$ increases, or the $F A \%$, the $C C C$ or the $r$ decreases. It should be noted that equation (14) works correctly if both the numerator and the denominator are positive and the $B$ has a value greater than 1 .

The importance of working capital management

The impact of working capital management on profitability is presented in figures 1 and 2 by changing the $C C C$ and setting the other parameters of equation (14) as constant in the FAM model. The $C C C$ gets values from zero to 100 . We have examined 
how the length of the $C C C$ affects the ROI on different levels of the FA\%, the EBITDA\%, the B and the r. The constant values are industry averages in the industrial maintenance service sector calculated with the data used in the empirical analysis. The range of each variable in figures 1 and 2 has been found realistic in the observed industry.

Figure 1. The ROI as a function of the $C C C$ and the FA\% (the chart on the left) and as a function of the $C C C$ and the EBITDA\% (the chart on the right). Here the B equals 8 years and the $\mathrm{r}$ equals -4 days.
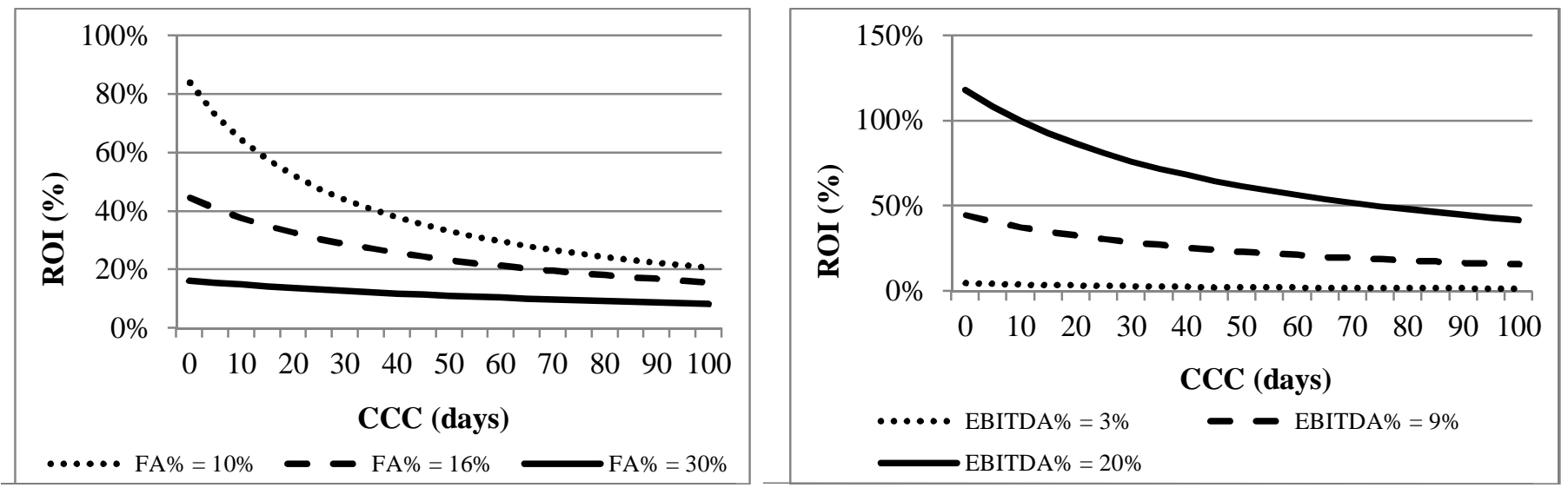

If the fixed asset ratio is high, the effect of the cycle time of working capital on profitability remains small. The impact of the $C C C$ on profitability is bigger in companies with flexible asset structures and a lower fixed asset ratio, and thus they should pay more attention to working capital management. For comparison, in a big customer industry of the industrial maintenance service sector, the pulp and paper industry, the FA\% is typically over $100 \%$. The length of the CCC gets more important when the EBITDA\% grows. If the EBITDA\% is low, efficient working capital management cannot save profitability, but on higher levels of the EBITDA, a long $C C C$ can destroy profitability.

Figure 2. The $R O I$ as a function of the $C C C$ and the B (the chart on the left) and as a function of the $C C C$ and the $\mathrm{r}$ (the chart on the right). Here the EBITDA\% equals $9 \%$ and the FA\% equals $16 \%$.
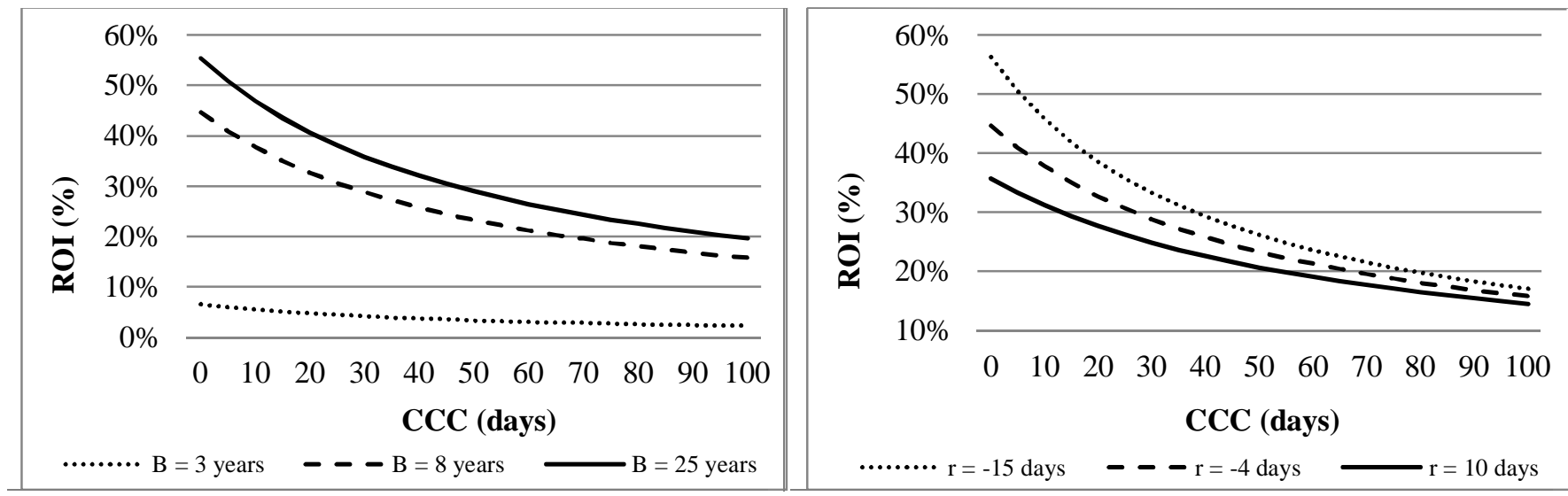

Since a low fixed asset ratio increases the impact of the $C C C$ on profitability, it is only logical that the same thing happens when the average depreciation period shortens. On the other hand, we can see that the shorter the residual term is, the more the $C C C$ affects the ROI. As regards the FA\%, the B and the $\mathrm{r}$, it must be noted, however, that minimizing them is not always the most viable solution. If anything, these parameters should be optimized on the basis of operational, tactical and strategic criteria. Especially the residual term, consisting of other current assets and other current liabilities, calls for further scientific research before any specific comment about the optimal value can be made. Based on this analysis we can now come to a conclusion that the characteristics of the industrial maintenance service sector strongly support the importance of working capital management practices. Operating with light fixed assets and high profitability makes these enterprises vulnerable to changes in profitability caused by fluctuation in the $C C C$.

\section{Comparing large enterprises and SMEs}

The parameters for the FAM model for all the enterprises in this research, large enterprises and SMEs separately, have been calculated as average values on the basis of the financial statements of the companies. These parameters are presented in table II. It can be noticed that the EBITDA\% is significantly higher in SMEs than in large maintenance service providers. However, 
when profitability is proportioned to the capital invested and the ROI is inspected, the situation changes. This indicates that the large maintenance service enterprises operate with exceptionally light balance sheets. For SMEs, the CCC is approximately 53 days, whereas for large companies the corresponding figure is roughly 9 days. When reviewing the components of the CCC in table II, it can be concluded that this difference mainly originates from the SMEs having notably longer cycle times for both accounts receivable and inventories. This may signal the existence of considerable economies of scale in the industrial maintenance sector. Large companies may have been able to shorten their DSO by using their bargaining power over their customers, whereas the bargaining power of SMEs over their customers is minor. It is notable that Hecker and Kretschmer (2010) suggest that economies of scale may also end in too powerful service providers which customers are starting to avoid. Thus economies of scale could convert into diseconomies of scale. Considering the DIO, on the other hand, the economies of scale in the industrial maintenance sector are quite different. Generally speaking, large maintenance service providers have more customers, facilities and equipment to be maintained, compared to SMEs. The risk of asset breakdown is thus usually divided between several units. In many respects, economies of scale originate from spare part inventory, because large enterprises can prepare for many risks with each spare part. It should also be noted that the FA\% is significantly larger for SMEs than for large enterprises. This may be due to economies of scale related to the use of fixed assets. Previous research suggests that economies of scale truly exist in the industrial maintenance business (Hecker and Kretschmer, 2010; Komonen, 2002; Martin, 1997).

Besides economies of scale, there is another explanation for the differences in the parameters between large enterprises and SMEs. It is notable that large enterprises in the Finnish industrial maintenance service sector are mostly focused on customers operating in specific industries. In fact many of the large service providers have been founded by manufacturing enterprises, who have wanted to outsource their maintenance. This has led to a situation where a vast majority of the net sales of most large maintenance service providers comes from their host companies. For SMEs, this kind of situation is not so common. Complete conclusions are difficult to make from this basis but close cooperation with their host companies may have had an influence on the studied parameters of large maintenance enterprises. At least the cycle time of accounts receivable, the cycle time of inventories, the fixed asset ratio and the residual depend on the contractual relation between host companies and service providers. The host companies may agree to short payment times, which would shorten the DSO. Some part of the inventories and the fixed assets of maintenance service providers can be owned and stored by their host companies, which reduces the DIO and the FA\%. Again, a large amount of receivables from group companies increase the sum of other current assets, which finally makes the $r$ larger. It would seem that the operations and the financial statements of the large maintenance service providers are affected by both the economies of scale and their host companies. It would be very important to know how strong impacts each of these aspects have, but this is left for further research.

Table II. Modeling parameters of industrial maintenance service providers (average numbers from 2004-2008).

\begin{tabular}{cccccccccc}
\cline { 2 - 9 } & EBITDA\% & FA\% & B (years) & $\begin{array}{c}\text { DSO } \\
(\text { days })\end{array}$ & $\begin{array}{r}\text { DIO } \\
\text { (days) }\end{array}$ & $\begin{array}{r}\text { DPO } \\
\text { (days) }\end{array}$ & $\begin{array}{c}\text { CCC } \\
(\text { days })\end{array}$ & r (days) & ROI \\
\hline $\begin{array}{c}\text { Large } \\
\text { enterprises }\end{array}$ & $5 \%$ & $8 \%$ & 6.9 & 15 & 9 & 15 & 9 & 7 \\
\hline SMEs & $10 \%$ & $20 \%$ & 7.8 & 45 & 22 & 14 & 53 & -10 & $23 \%$ \\
\hline $\begin{array}{c}\text { All } \\
\text { enterprises }\end{array}$ & $9 \%$ & $16 \%$ & 7.5 & 37 & 18 & 14 & 41 & -4 & $24 \%$ \\
\hline
\end{tabular}

The EBITDA\%, the FA\%, the B and the $\mathrm{r}$ have been set constant in the FAM model for large maintenance service providers and SMEs separately. We have varied the length of the CCC in order to define the impact on the ROI. Figure 3 shows how the ROI changes for SMEs and for large enterprises. The actual situation for each group is depicted with the vertical lines. The difference between SMEs and large enterprises is remarkable considering the length of the $C C C$. Arising from the shape of the relation between the $C C C$ and the ROI, this means that for large enterprises changes in the $C C C$ have a more extensive effect on the $R O I$. Thus particularly the large industrial maintenance service providers should pay attention to working capital management. The profitability of individual customers can easily be ruined with neglectful policies during the contract formulation. Also Hatinen et al. (2011) remark that working capital management is more important for large maintenance service providers than for SMEs. They have come to this conclusion by noticing that in large maintenance enterprises the share of working capital investments in total investments is remarkably larger than in SMEs. On the other hand, it can be seen from figure 3 that the potential for improvements is more extensive for SMEs than for large companies due to the larger value of the $C C C$. 
Figure 3. The impact of the $C C C$ on the profitability of large companies and SMEs in the maintenance industry. The vertical lines indicate the actual situation of the enterprises.

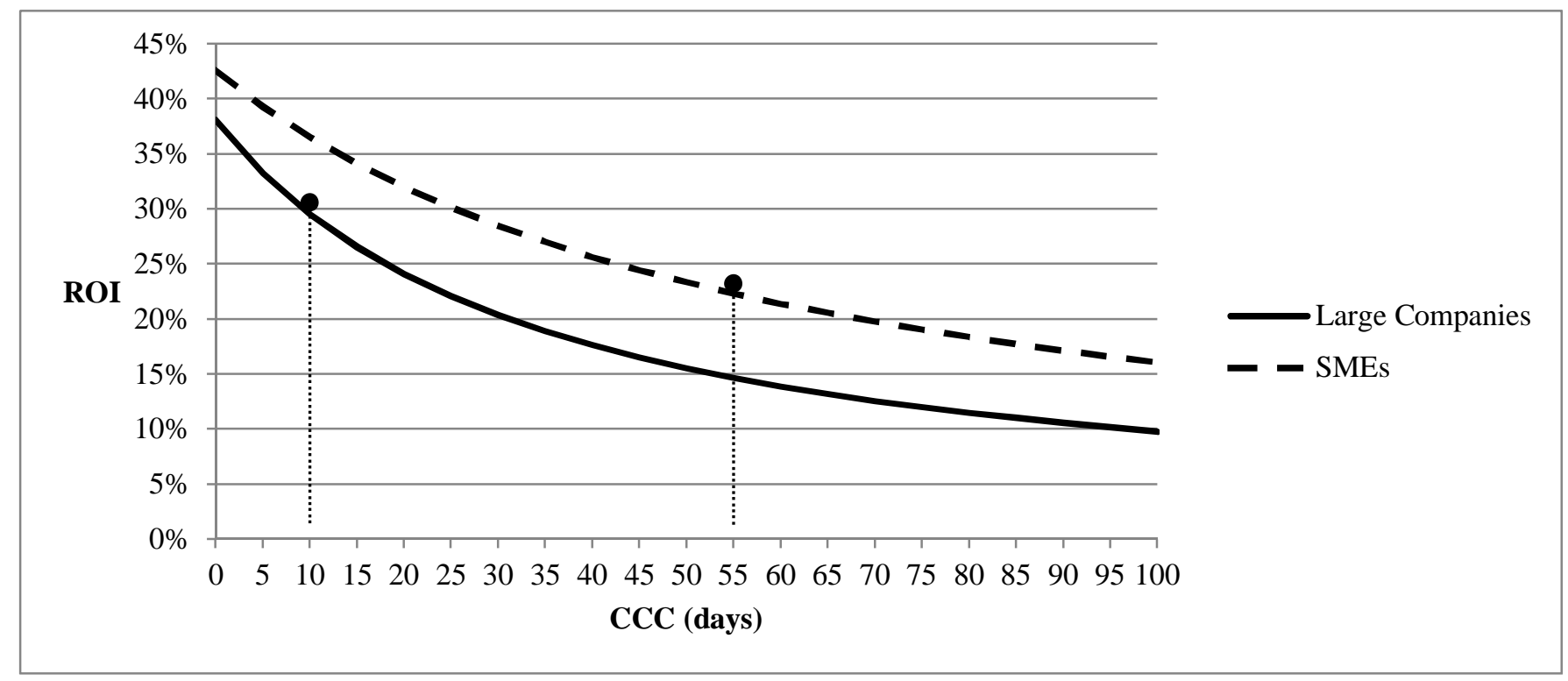

\section{Analyzing the future possibilities}

The maintenance service sector is further explicated through inspecting some future possibilities which are built using the FAM model. The past economic crisis has reshaped the profitability of the maintenance service providers in an unknown way. The FAM model is a valuable management tool especially under this kind of hard circumstances. In order to restore their profitability, companies can either manage their working capital or adjust their fixed assets. Our analysis helps to understand how a target level of the ROI can be achieved through different combinations of the CCC and the EBITDA\%. In other words, it is studied how the changes of the EBITDA\% can be compensated with the working capital management, so that the ROI will not suffer. It should be remembered that the EBITDA\% depends on the sales as well as on the fixed and variable costs of the company. Only the $C C C$ and the EBITDA\% have been varied in this analysis, thus the ROI, the FA\%, the $\mathrm{B}$ and the $\mathrm{r}$ are set constant. This is justified, because altering the amount of the fixed assets is a long-term strategy for adaptation, while our analysis focuses on short- and medium term. In addition, it is not common to make investments during the recession, while the companies already have idle capacity. The behavior of the residual term, on the other hand, remains somewhat obscure, which is why we have decided to set $\mathrm{r}$ constant and to define the ROI as a function of only the $C C C$ and the EBITDA\%. The period analyzed here is the five-year period from 2009 to 2013. Assuming that the economical crisis depresses the ROI in 2009-2010, but otherwise the maintenance service sector is growing and profitable, we have set the target values of the ROI for the period 2009-2013 to the same level as were the average values in 2004-2008 for the large maintenance service providers and the SMEs separately. The results of the analysis are presented visually in figure 4, where the target value of the ROI is $30 \%$ for large enterprises and $23 \%$ for SMEs. The vertical lines indicate the actual situation of the enterprises in 2004-2008. Very small positive values or any negative values for the EBITDA\% are not included in the analysis due to the current limitations of the FAM model. In practice this does not matter, because the resulting graphs are linear: the values of the $C C C$ which are required to compensate the small and negative values of the EBITDA\% can be defined through simple extrapolation. 
Figure 4. The combinations of the $C C C$ and the EBITDA\% with which the target values of the ROI can be achieved in large maintenance enterprises and SMEs separately.

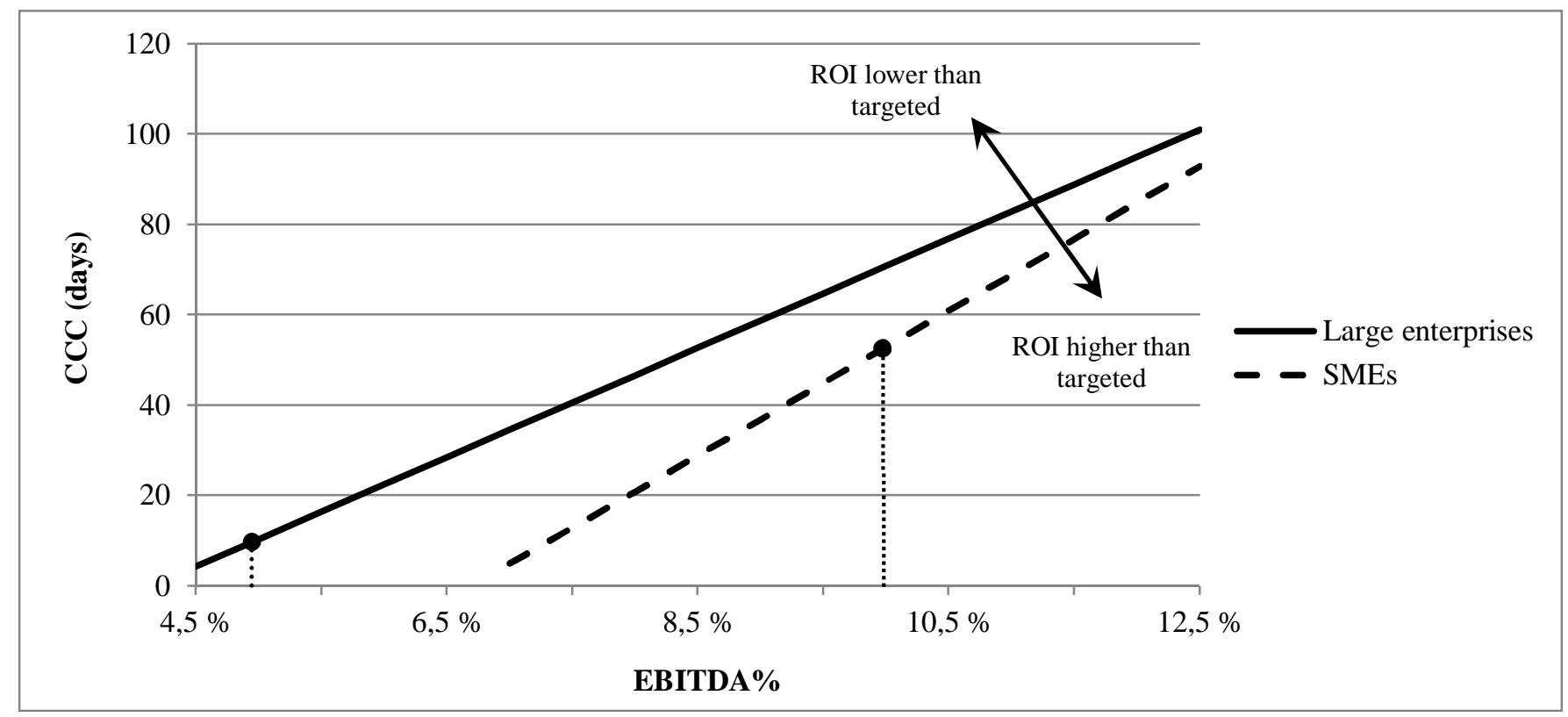

It can be seen from figure 4 that the changes of the EBITDA\% have a considerable effect on the ROI, which means that it is very difficult to compensate these changes completely by altering only the $C C C$. In addition, in practice the difference between the $D S O$ and the $D P O$ tends to remain nearly constant within companies, so that the required changes of the $C C C$ depend greatly on the changes of the DIO. On the other hand, the growth of the EBITDA\% improves the value of the ROI extensively, and therefore any small increase of the $C C C$ does not drop the ROI below the target value. It is interesting to notice that the graph of the large enterprises goes above the curve of the SMEs. This indicates that for each value of the EBITDA\%, the large enterprises can achieve their target ROIs with longer $C C C$ s. The area in which the combination of the $C C C$ and the EBITDA\% results in a ROI higher than targeted is more extensive for the large enterprises compared to the SMEs. In order to determine the reasons behind this phenomenon, we have solved the $C C C$ from equation (14). This has left us with equation (15).

$$
C C C=\frac{365 \cdot\left[E B I T D A \%-\left(F A \% \cdot \frac{1}{B-1}\right)\right]}{R O I}-r-365 \cdot F A \%
$$

From equation (15) it can be concluded that the $C C C$ increases if ceteris paribus the $R O I$, the $F A \%$, or the $r$ decreases, or if the $B$ increases. However, from table II it can be seen that the ROI and the $r$ are higher in the large enterprises than in the SMEs, whereas the $F A \%$ and the $B$ are lower in the large enterprises compared to the SMEs. Thus the $F A \%$ is the only variable out of these four which actually supports the higher values of the $C C C$ for the large enterprises in figure 4 . We can now conclude that the impact of the $F A \%$ on the $C C C$ outdoes the synergetic contradictory impact of the other three variables. Thus the large maintenance service providers have a competitive advantage over the SMEs due to their lower fixed assets ratio. This notice is interesting, because it is often assumed that large maintenance companies are more capital intensive than maintenance SMEs.

\section{Discussion}

This paper has shed light on the impact of working capital management on the ROI in the industrial maintenance service sector. Considering the managerial implications of this study, we now know that in the industrial maintenance service business attention should be paid to active management of working capital. We can conclude that this holds true especially in large industrial maintenance service enterprises. Previous studies of industrial maintenance companies have not addressed working capital management, which gains more and more attention under the volatile economic circumstances of the present day. There is a growing need for management tools that focus on the impact of working capital management on profitability. It should be noted that while the paper focuses on Finnish maintenance providers, the model and the logic presented here can be applied to a variety of industries and countries.

The FAM model can be utilized as a tool in decision-making in firms, both in the short term and in the long term. For example in contract-bound industries the FAM model can be used when negotiating with customers or suppliers to point out any changes in contract profitability caused by for example different terms of payment or arrangements of the ownership of assets. In the long term, decision-makers can use the model to discover any positive or negative trends in the development of their firm, and finally to forecast the future development.

The sample used in empirical analysis represents the Finnish industrial maintenance service sector well. However, the scarcity of large enterprises in the market in question must be included in our research limitations, because any single 
abnormalities in numerical values affect the average values excessively. Another limitation is the absence of the latest financial statements of the studied enterprises. Further research can also include international comparative research about working capital management in industrial maintenance companies. However, in Finland the terms of payment are generally strict, and the agreements are adhered to. This may not be the case elsewhere, which would bring additional challenges into working capital management.

Concerning the generality of our results, it can be said that in addition to the industrial maintenance service business, many of our conclusions also hold true in other industries. For example, the impact of the $C C C$ on the ROI extends while the fixed assets, the average depreciation period or the residual decrease, or when the operating margin ratio increases. This supports the importance of working capital management in unconventional industries, for example in many service industries. It should be further examined how important a role economies of scale truly have in the industrial maintenance business. On the other hand, providing services mostly for their host companies has an impact on the operations and financial statements of Finnish industrial maintenance service enterprises. The role of this impact would also be important for both academics and the decision-makers of firms to know. Objectives for further research also include discussing the residual term consisting of the other current assets less the other current liabilities. The behavior of this variable should be defined so that decision-makers can optimize its value.

\section{Conclusions}

The analytical FAM model shows that ceteris paribus the return on investment $(R O I)$ correlates negatively with the length of the cycle time of operational working capital $(C C C)$. Other parameters affecting the return on investment are the operating margin ratio, the fixed asset ratio, the average depreciation period and the residual term, consisting of the other current assets and the other current liabilities. The effect of the $C C C$ on the $R O I$ is especially strong in the industrial maintenance service sector, arising from light fixed assets and good profitability. Interestingly, the $C C C$ is notably shorter in large Finnish maintenance service enterprises than in SMEs of the same industry. This means that changes in the $C C C$ have a much more extensive impact on the ROI in large maintenance service providers. The difference between large enterprises and SMEs can be explained through both fixed assets- and working capital-related economies of scale, and the fact that large maintenance service providers often focus on providing services mostly for their host companies. The changes of the EBITDA\% affect ROI so much that compensating them with the management of the cycle times of working capital is unrealistic in maintenance service companies. Especially in large enterprises the $C C C$ cannot be shortened. However, the large enterprises seem to have a competitive advantage over the SMEs due to lower fixed assets ratios.

\section{References}

Al-Turki, U. (2011), “A framework for strategic planning in maintenance”, Journal of Quality in Maintenance Engineering, Vol. 17 No. 2, pp. 150-162.

Aoudia, M., Belmokhtar, O. and Zwingelstein, G. (2008), "Economic impact of maintenance management ineffectiveness of an oil and gas company”, Journal of Quality in Maintenance Engineering, Vol. 14 No. 3, pp. 237-261.

Bailey, W., Masson, R. and Raeside, R. (2002), "Outsourcing in Edinburgh and the Lothians", European Journal of Purchasing \& Supply Management, Vol. 8 No. 2, pp. 83-95.

Baños-Caballero, S., García-Teruel, P. and Martínez-Solano, P. (2010), “"Working capital management in SMEs", Accounting and Finance, Vol. 3 No. 50, pp. 511-527.

Benson, J. and Ieronimo, N. (1996), "Outsourcing decisions: evidence from Australia-based enterprises", International Labour Review, Vol. 135 No. 1, pp. 59-73.

Blinder, A.S. and Maccini, L.J. (1991), “The resurgence of inventory research: what have we learned?", Journal of Economic Surveys, Vol. 5 No. 4, pp. 291-328.

Boulaksil, Y. and Fransoo, J.C. (2010), "Implications of outsourcing on operations planning: findings from the pharmaceutical industry”, International Journal of Operations \& Production Management, Vol. 30 No. 10, pp. 1059-1079.

Broedner, P., Kinkel, S. and Lay, G. (2009), "Productivity effects of outsourcing - new evidence on the strategic importance of vertical integration decisions", International Journal of Operations \& Production Management, Vol. 29 No. 2, pp. $127-150$.

Campbell, J. (1995), “Outsourcing in maintenance management. A valid alternative to self-provision”, Journal of Quality in Maintenance Engineering, Vol. 1 No. 3, pp. 18-24.

Chiou, J., Cheng, L. and Wu, H. (2006), "The determinants of working capital", The Journal of American Academy of Business, Vol. 1 No. 10, pp. 149-155.

Deloof, M. (2003), “Does working capital management affect profitability of Belgium firms?”, Journal of Business Finance \& Accounting, Vol. 30 No. 3-4, pp. 573-587.

Demski, J.S. (2007), “Analytic modeling in management accounting research”, in Chapman, C.S., Hopwood, A.G. and Shields, M.D. (Ed.), Handbook of Management Accounting Research, Elsevier, Amsterdam, pp. 365-371. 
Dong, H.P. and Su, J. (2010), "The relationship between working capital management and profitability: a Vietnam case", International Research Journal of Finance and Economics, Vol. 5 No. 49, pp. 59-67.

Duffy, R. (2008), "Towards a better understanding of partnership attributes: an exploratory analysis of relationship type classification”, Industrial Marketing Management, Vol. 37 No. 2, pp. 228-244.

European Commission. (2009), "Definition of micro, small and medium-sized enterprises adopted by the commission”, available at: http://eur-lex.europa.eu/LexUriServ/LexUriServ.do?uri=OJ:L:2003:124:0036:0041:en:PDF (accessed 6 May 2011).

García-Teruel, P.J. and Martínez-Solano, P. (2007), "Effects of working capital management on SME profitability", International Journal of Managerial Finance, Vol. 2 No. 3, pp. 164-177.

Harland, C., Knight, L., Lamming, R. and Walker, H. (2005), "Outsourcing: assessing the risks and benefits for organizations, sectors and nations", International Journal of Operations \& Production Management, Vol. 25 No. 9, pp. 831-850.

Hatinen, L., Pirttilä, M., Viskari, S. and Kärri, T. (2011), "Investment logics of Finnish industrial maintenance service providers", [manuscript accepted for publication in International Journal of Strategic Engineering Asset Management].

Hecker, A. and Kretschmer, T. (2010), "Outsourcing decisions: the effect of scale economies and market structure", Strategic Organization, Vol. 8 No. 2, pp. 155-175.

Hendry, J. (1995), "Culture, community and networks: the hidden cost of outsourcing”, European Management Journal, Vol. 2 No. 13, pp. 193-200.

Hill, M.D., Kelly, G.W. and Highfield, M.J. (2010), "Net operating working capital behavior: a first look", Financial Management, Vol. 39 No. 2, pp. 783-805.

Hilletofth, P. and Hilmola, O-P. (2010), "Role of logistics outsourcing on supply chain strategy and management. Survey findings from Northern Europe", Strategic Outsourcing, Vol. 3 No. 1, pp. 46-61.

Holschbach, E. and Hofmann, E. (2011), “Exploring quality management for business services from a buyer's perspective using multiple case study evidence", International Journal of Operations \& Production Management, Vol. 31 No. 6, pp. 648-685.

Hui, E. and Tsang, A. (2006), "The inter-organizational relationship in a multi-contractor business network", Journal of Quality in Maintenance Engineering, Vol. 12 No. 3, pp. 252-266.

Johnson, M. and Templer, S. (2011), "The relationships between supply chain and firm performance: the development and testing of unified proxy”, International Journal of Physical distribution \& Logistics Management, Vol. 2 No. 41, pp. 88-103.

Jose, M., Lancaster, C. and Stevens, J. (1996), "Corporate returns and cash conversion cycles", Journal of Economics and Finance, Vol. 1 No. 20, pp. 33-46.

Kakabadse, A. and Kakabadse, N. (2002), "Trends in outsourcing: contrasting USA and Europe", European Management Journal, Vol. 2 No. 20, pp. 189-198.

Komonen, K. (2002), "A cost model of industrial maintenance for profitability analysis and benchmarking", International Journal of Production Economics, Vol. 79 No. 1, pp. 15-31.

Komonen, K. (2009), "Challenges 2009 - the current and future challenges of maintenance in Finland", Promaint, Vol. 3 No. 23, pp. 18-22. (in Finnish).

Komonen, K. (2010), “Asset management in the industrial sector: background and conceptual approach", Maintworld, Vol. 2 No. 1, pp. 16-19.

Kornev, A.K. (2009), "Possibilities of rapid renewal of active part of fixed assets of branches of industry", Studies on Russian Economic Development, Vol. 5 No. 20, pp. 563-567.

Kremic, T., Tukel, O.I. and Rom, W. (2006), "Outsourcing decision support: a survey of benefits, risks, and decision factors", Supply Chain Management: An International Journal, Vol. 6 No. 11, pp. 467-482.

Kumar, R. and Kumar, U. (2004), "A conceptual framework for the development of a service delivery strategy for industrial systems and products", Journal of Business \& Industrial Marketing, Vol. 5 No. 19, pp. 310-319.

Kumar, R., Markeset, T. and Kumar, U. (2004), "Maintenance of machinery. Negotiating service contracts in business-tobusiness marketing", International Journal of Service Industry Management, Vol. 15 No. 4, pp. 400-413.

Kärri, T. (2007), Timing of capacity change: models for capital intensive industry, Acta Universitatis Lappeenrantaensis 287, Dissertation, Lappeenranta University of Technology, Lappeenranta.

Lazaridis, I. and Tryfonidis, D. (2006), "Relationship between working capital management and profitability of listed companies in the Athens stock exchange", Journal of Financial Management and Analysis, Vol. 19 No. 1, pp. 26-35. 
Martin, H.H. (1997), “Contracting out maintenance and a plan for future research", Journal of Quality in Maintenance Engineering, Vol. 3 No. 2, pp. 81-90.

McIvor, R., Humphreys, P., McKittrick, A. and Wall, T. (2009), "Performance management and the outsourcing process lessons from a financial services organization”, International Journal of Operations \& Production Management, Vol. 29 No. 10, pp. 1025-1048.

Miles, R. and Snow, C. (1986), “Organizations: new concepts for new forms”, California Management Review, Vol. 3 No. 28, pp. 62-73.

Molina, C.A. and Preve, L.A. (2009), "Trade receivables policy of distressed firms and its effect on the costs of financial distress", Financial Management, Vol. 3 No. 38, pp. 663-686.

Ng, C.K., Smith, J.K. and Smith, R.L. (1999), "Evidence on the determinants of credit terms used in interfirm trade", Journal of Finance, Vol. 54 No. 3, pp. 1109-1129.

Ngwenyama, O. and Bryson, N. (1999), "Making the information systems outsourcing decision: a transaction cost approach to analyzing outsourcing decision problems", European Journal of Operational Research, Vol. 115 No. 2, pp. 351-367.

Prahalad, C.K. and Hamel, G. (1990), “The core competence of the corporation”, Harvard Business Review, Vol. 68 No. 3 , pp. 71-91.

Redondo-Cano, A. and Canet-Giner, M.T. (2010), “Outsourcing agrochemical services: economic or strategic logic?", Service Business, Vol. 4 No. 3-4, pp. 237-252.

Reed, R. and Storrud-Barnes, S. (2009), "Systematic performance differences across the manufacturing-service continuum", Service Business, Vol. 4 No. 3, pp. 319-339.

Simões, J.M., Gomes, C.F. and Yasin, M.M. (2011), "A literature review of maintenance performance measurement. A conceptual framework and directions for future research", Journal of Quality in Maintenance Engineering, Vol. 17 No. 2, pp. 116-137.

Tam, A.S.B. and Price, J.W.H. (2008), “A maintenance prioritization approach to maximise return on investment subject to time and budget constraints", Journal of Quality in Maintenance Engineering, Vol. 14 No. 3, pp. 272-289.

Tarakci, H., Tang, K. and Teyarachakul, S. (2009), "Learning effects on maintenance outsourcing", European Journal of Operational Research, Vol. 192 No. 1, pp. 138-150.

The European Federation of National Maintenance Societies. (2011), "Intermediate results of the asset management survey for all national maintenance societies”, available at: http://e-lomake.fi/raportti/efnms_2011_survey (accessed 1 August 2011).

The Finnish Maintenance Society. (2007), "Maintenance in national economy of Finland", available at: http://www.promaint.net/alltypes.asp?menu_id=348 (accessed 5 May 2011). (in Finnish).

Viskari, S., Lukkari, E. and Kärri, T. (2011), “State of working capital management research: bibliometric study”, Middle Eastern Finance and Economics, June 2011, No. 14, pp. 99-108.

Wang, Y.J. (2002), "Liquidity management, operating performance, and corporate value: evidence from Japan and Taiwan", Journal of Multinational Financial Management, Vol. 12 No. 2, pp. 159-169. 